\title{
Inequity in the Provision of Public Bus Service for Socially Disadvantaged Groups
}

\author{
Ali Soltani \& Yousef Esmaeili Ivaki \\ Department of Urban Planning, Faculty of Art and Architecture \\ Shiraz University, Iran
}

Received: March 15, 2011

Accepted: July 25, 2011

doi:10.5539/jsd.v4n5p229

\begin{abstract}
The neo-classical and the economic doctrines dominating the governmental policies show their impact on the recent transportation policies, basing these policies on the demand and the efficiency criteria instead of the equity concerns. The public transit system operating for the remote areas is less cost-effective, eventually leading to reach a low level of service quality. In the metropolitan areas of the developing countries, a large part of the socially disadvantaged and vulnerable groups live in the outer suburban locations rather than in the inner-city districts. An evaluation of the transit equity is required in order to consider the requirements of the more vulnerable populations, and also to foster equal benefits. The evaluation approach is based on highlighting the spatial distribution and clustering the patterns of the bus network and service as well as the patterns of some disadvantaged social groups including the unemployed, migrated, less educated, elderly, young, and disabled ones. The hypothesis is that the vulnerable groups and the economically disadvantaged communities receive a less-than-equal share of the public bus services. The findings of the study show that the poor accessibility is associated with both the low-income neighborhoods and the neighborhoods with disproportionately high populations of the migrated, less-educated, unemployed, and low-income groups. Modifications need to be made in the transportation planning and the policy system so as to achieve a better distribution of the public transportation services in the hope of increasing the level of service for the minority groups and the economically disadvantaged communities.
\end{abstract}

Keywords: Social sustainability, Vulnerable groups, Transportation, Public policy

\section{Introduction}

Public transit is one of the most social services these days. A reliable public transit is crucial to get sustainable access to job, education, health care, and recreation (Garrett \& Taylor, 1999). Furthermore, despite the growing trend of the private vehicle ownership and use, a considerable part of the middle- and low-income people uses the public transit for several reasons. Inequity in the provision of the public transportation service may limit their access to the opportunities, so that it puts the society in a sort of discrimination. The neo-classical and the economic doctrines dominating the governmental policies show their impact on the recent transportation policies, basing these policies on the demand and the efficiency criteria instead of the equity concerns.

The public transit system operating for the remote areas is less cost-effective, eventually leading to reach a low level of service quality. At the same time, a large part of the socially vulnerable groups live in the outer suburban locations rather than in the inner-city districts. The poor residents in the developed countries choose to live in the depressed urban cores due to the high cost of transportation in contrast to those in the developing countries who choose to live at the fringes. Because of their physical location as well as their economic affordance, they usually need more time, greater effort, and higher marginal capital to reach the same destinations as the people owning cars living in the inner areas. Therefore, the outer residents meet some problems with regard to accessing jobs, education/training opportunities as well as the suitable accommodation services (e.g. healthcare, social support and benefits). Such problems are more evident in the remote suburbs and the urban fringes where the majority of the low-income people and the migrants live in. A large body of research can be found discussing whether the residential locations of the socially vulnerable groups are significantly associated with the distribution of the urban facilities. However, in spite of the growing body of literature, few empirical studies have examined the issue of equity within the context of the public transportation services.

This research is an attempt to address this gap in the literature through evaluating the implications of the social equity in the public bus facilities of the metropolitan Shiraz, located in the South of Iran. Shiraz, a regional city of growing population and strong dependence on motor vehicles, was chosen as the focus area of the present 
study on the basis of the information availability. The hypothesis is that a lower share of the public bus facilities can be expected for those residential districts where a greater proportion of the socio-economically disadvantaged citizenry reside. Therefore, the spatial distribution of the public bus service supply was examined against the travel location of the disadvantaged groups including the unemployed, immigrated, less-educated, young, aged and disabled ones.

\section{Materials and Methods}

\subsection{Main Concepts}

Equity is generally defined as the quality of being fair and impartial (Oxford Dic. website, 2011). The social equity is a goal for the sustainable societies, and implies a fair access to livelihood, education, and resources; the full participation in the political and cultural life of the community; and the self-determination in meeting the fundamental needs (Wikipedia, 2011). The spatial equity provides an equal access to the basic public facilities (Talen \& Anselin, 1998). It concerns with "the amount of the resource being spatially distributed to the users and the threshold it may meet their needs" (Smoyer-Tomic et al., 2004). The definition for the disadvantaged groups may vary among countries and regions, but some of the most important defining characteristics are age, sex, ethnicity, and location. But also important are people with disabilities and stigmatized illnesses, such as mental retardation. Such social groups generally are supposed to have some additional needs, thus, requiring specific support.

The equity planning can be defined as providing more choices to those residents who have few choices (Garrett \& Taylor, 1999). The spatial equity in the transportation planning could be defined as the fair distribution of the transportation facilities and services among the citizens regardless of their color, race, sex, income, or nationality (Litman, 2011). The transportation disadvantage, which has been defined by Dodson et al. (2004), is a "social, economic, labor market, or housing condition of disadvantage in which the transportation plays a crucial role" ( $\mathrm{p}$. 5). Generally, the low rates of the car ownership, the inaccessible public transportation services, the unresolved road and pedestrian/cycle networks, and the poor quality of the transportation infrastructure, like other forms of social disadvantages, limit the potential of the residents and the areas. The transportation disability has been defined as the unnecessary exclusion of the disabled people from the current forms of transportation (Heiser, 1995). Hurrni (2006) proposed that the transportation disadvantage exists where the people with the mobility constraints live in the areas of restricted accessibility. The mobility constraints are linked to the operating regimes: fixed routes, tight scheduling, little time to get on and off, and the passengers conforming to the schedule rather than vice versa (Wilson, 2003). The Australian National Road and Motorists Association (NRMA), in a report on the transportation access, found that the transportation disadvantage generally occurs to disabled and isolated people, youths, students, children, unemployed people, immigrants, single parents, and the low income households (Johnson, 2005).

\subsection{Approaches of evaluating inequity in the literature}

There are a number of spatial and statistical methods applied so far to determine whether the residential location of the ethnic and racial minority and the economically deprived groups are associated with the distribution of the urban facilities. The capability of GIS is an effective tool in the spatial statistical analysis since it provides a powerful way to obtain comprehensive information to analyze and visualize the impacts and the benefits among the populations over space. The well-known ESDA (Exploratory Spatial Data Analysis), as a set of spatial statistics tools, enables us to explicitly model the spatial interactions, and identify the importance of the space, location, and distance in a variety of neighborhood processes (Messner et al., 1999).

The impacts of the transportation disadvantage are often derived from the accessibility and activity-based impacts, such as the difficulty in accessing the work, healthcare, education, or social activities (Delbosc \& Currie, 2011). The spatial equity is generally examined through applying the accessibility indicators. Accessibility is defined as the relative nearness or the proximity of one place to another (Tsou et al., 2005). In a broader term, the accessibility means the ease of reaching the opportunities within a reasonable time, cost, and comfort. While the proximity is a simple distance measurement, the accessibility takes into account further factors such as the modal access (Dodson et al., 2004). The accessibility is highly related to the potential opportunity provided by the land-use and the transportation system for different types of people to be engaged. However, it is a spatial analytic measure which plays a key role to evaluating the geographical location of the public facilities against their expediency.

A simple measure of transportation accessibility against the disadvantaged areas used by Hurrni (2006) was the proximity of 800 meters to a transit stop. It was found that the relationship between transportation and social exclusion is complex, as experienced in a number of locations in the Western Sydney. The transportation 
disadvantage is not a peculiarity of a specific location to the extent that it can only be addressed at a local level. Rather, there are enough similarities in the experience of the population groups, across locations, in terms of their travel and transportation needs, to warrant a systematic change in the delivery of the transportation services (Hurrni, 2006). However, there should also be some opportunities for flexibility to adapt the transportation services to the localized factors. Grengs (2001) developed a GIS-based accessibility indicator and applied it to the examination of the accessibility to the supermarkets in Syracuse, New York. The study confirmed that the poor accessibility is associated with both the low-income neighborhoods and the neighborhoods with the disproportionately high populations of African-Americans. Wang (2003), in a study on the workers of Cleveland in US, introduced two different indices, i.e. job proximity and job accessibility, to measure the workers' location advantage with residences regarding their job markets. He found that while the low-income workers enjoy a proper physical proximity to job locations, their accessibility still remains poor due to the low levels of car ownership. The job proximity declines with the distance from the CBD, and conforms to the mono-centric model as the job accessibility does, but to a low extent. Since the workers with various incomes respond differently to the job access, the distribution of the mean income rates in the metropolitan area is hardly mono-centric. Currie et al. (2010) tried to analyze the mismatch between the public transportation supply and the social needs in the Australian city of Perth. They applied a quantitatively-based approach utilizing GIS techniques to objectively evaluate the relative needs of the social groups and the service levels. Johnson (2005) used the community mapping technique to investigate the connection among the transportation access, transportation disadvantage, and the social exclusion through the documentation of the experiences of the transportation users of Goodna in the Western suburbs of Brisbane, Australia. The research tried to clearly identify the potential and the actual barriers for the transportation disadvantaged groups.

The literature confirms that the transportation system can either facilitate the social inclusion or exacerbate the social exclusion. The main methodological approaches of examining this claim have been modeled: the GIS and the statistical manipulation which are noted as being more appropriate to the macro-scale level of analysis, and the qualitative approach. Although most of the past studies have considered the physical access to the public transportation service as a measure of social equity, this research argues that having the physical access to a public transportation network does not guarantee that the level of the service along that route will be of a quality that permits high levels of mobility, or access to the services. Other aspects of the transit quality, such as punctuality, reliability, and comfort, should be considered. An inventory measure of the frequency density is applied here in addition to considering the physical proximity. The details are discussed in the second part.

\subsection{The empirical case study}

\subsubsection{The research area}

This section introduces the case study area and its characteristics. The geographical area of this research is Shiraz metropolitan area and its public bus system is evaluated against the social equity. Shiraz is one of the most important cities of Iran which is well-known as the cradle of the Persian civilization and its history dates back to 4'000 years ago. It is the capital of Fars Province, and tagged as the poetic capital of Persia. Shiraz was the home city of the great poets $S a^{\prime} d i$ and Hafez. The population of Shiraz is around 1.5 million now and it is the fifth largest city in Iran in terms of population. According to a recent survey, the shares of the different modes of travel in this city are as follows: private cars and taxis: 60 percent, buses: 30 percent and the other modes: 10 percent which is an unsustainable trend in a longer term. Therefore, the public bus is the main mode of public transportation (TEAM, 2008). The metropolitan area consists of 9 Zones each of which has its own municipal authority.

The data on the number and the location of the bus stops and the bus lines in Shiraz were obtained from Shiraz Organization of Public Bus (SOPB), Municipality of Metropolitan Shiraz, with some modifications made by the authors. The sum of over 1500 bus stops and 71 bus lines was included in the analysis. The measures of the bus access were calculated with ESRI ArcGIS Network Analyst Version 9.3, using the distance inputs as the shortest path distances over the actual street network between the centroids of each census tract and the bus stop location. The GIS calculation showed that almost all the residents (90.2 percent) are within the 400 meter walk access to the bus stops. Although the bus stops are in the vicinity of 400 meters from the blocks, the alternatives in choosing the lines are completely limited. The simple proximity to a bus stop or route, in fact, does not guarantee that the level of the service along that route will be of a quality that permits high levels of mobility, or access to the services. Therefore, a new index was defined as the bus service frequency for each line.

The newest census data for Shiraz was released in 2006. Based on this database, a census tract (block) was selected as the spatial and the sampling unit of the analysis since it is the smallest geographical unit for which 
some significant socio-economic data is available. It should be noted that some tract groups were excluded because of the deficiency in the quality of the data. This resulted in a data set of 10'471 observations. The average area of a census tract is 9057 square meters. In terms of the population, each tract has an average population of 126.5 people and the standard deviation of the tract population is 272.2 people, showing a considerable variance among the tracts in which the population resides. According to the above information, the average density of the tract population is 0.027 persons per area (square meters). Since no robust data on the household income was available, two variables including the building floor area and the index of Zonal Property Price (published by Shiraz Municipality, 2008) were combined to estimate the property value, which is the residents' affluence. The spatial distribution of the social groups throughout the metropolitan area shows that low-income groups live mostly on the South and the South-Western and Eastern fringes as well as in the central old fabric of the city. Of course, the distribution of the low-income groups is not homogenous since they can be found in other parts of the metropolitan area, such as the North and the North-East.

The following attributes were taken into account in order to subdivide the population for the purposes of addressing the social equity: employment, immigration, literacy status, age, and disability. The disadvantaged groups include those who are in, at least, one of following categories: unemployed, migrated, less-educated, young (between 6 and 25), old (over 65), and disabled. The spatial association between these variables and the bus accessibility (defined as the bus frequency level serving the area) was examined. The statistical description of the variables is detailed on Table 1 .

\section{\{Insert Table 1 here\}}

\subsubsection{Empirical analysis}

Based on the bus frequency index introduced earlier, a density map can be generated with the variable of the frequency of each line after intersecting it with the census tract boundaries. This measure will also be used for the assessment of the social equity. The bus frequency level is very high for the CBD and the neighboring areas. It is also considerable for those main routes ending to CBD (Figure 1). Comparing the distribution of the bus service (based on the density frequency of the network) with those maps showing the spatial pattern of the socio-economic characteristics, we can claim that the issue of inequity in the distribution of the bus services is related to the geographic distribution of Shiraz economy, education, and employment groups. The shares of unemployment, immigration, and young generation are significantly higher in the South-East and the urban fringes than any other parts. This means that the outer areas are occupied by the young residents who are not Shiraz-born, and look for jobs. They definitely need a reliable bus service. The illiteracy rate is high for the old fabric of the central area (Zone 8) due to the presence of the foreign immigrants mostly from Afghanistan. The pattern of the disability distribution is not clustered since the disabled people can be found anywhere among all the social groups. Finally, the distribution of the elderly people shows that the senior residents are more likely to live in the central districts and less in the remote areas. An explanation for this might be their potential need to the healthcare and other public services which are more accessible in the central area.

\section{\{Insert Figure 1 here\}}

The objective of the analysis is to find out how much each feature is similar (or dissimilar) to its neighbors. This can be achieved through doing the spatial autocorrelation (Anselin \& Bera, 1998). This allows an examination of the clustering of the neighborhoods with high and/or low levels of access to the bus services (or any other variable). Moran's $I$ is a statistical formula which is suggested to measure the spatial autocorrelation of an attribute. It is calculated as follows:

$$
I=\frac{N \sum_{i} \sum_{j} w_{i j}\left(x_{i}-\bar{x}\right)\left(x_{j}-\bar{x}\right)}{\left(\sum_{i} \sum_{j} w_{i j}\right) \sum_{i}\left(x_{i}-\bar{x}\right)^{2}}
$$

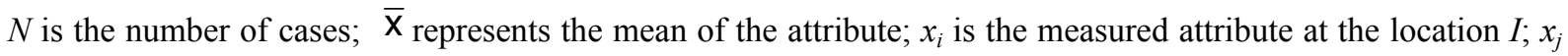
deals with the measured interest attribute at the location $j$; $w_{i j}$ is a weight indexing the location of i relative to $j$ (Winona State University, 2011). The range of Moran's I is between -1 to 1. If all the neighboring features had been close to the same value, the result would be near 1 showing a full clustering. In contrast, if the values are completely dispersed, then the value of $I$ will be close to -1 . On the other hand, if there are roughly as many pairs with positive cross-products as there are with negative cross-products, then the resulting Moran's I value will be close to zero. This indicates a random distribution. Therefore, the higher values reflect a positive spatial 
autocorrelation, or the concentration of the similar values of the observation. Conversely, the lower values reflect a negative spatial autocorrelation, or the spreading of the similar values of the observation over space. Another important feature deals with testing the significance of Moran's $I$ is to make sure that the pattern is not simply due to the chance. This can be done through calculating a Z-score with the following formula applied by ArcGIS:

$$
\mathrm{Z}-\text { score }=\frac{\mathrm{I}-\mathrm{E}(\mathrm{I})}{\mathrm{Std} \operatorname{Dev}}
$$

In this formula, $E(I)=-1 /(N-1)$ and the Standard Deviation is based on the number of the data points, the number of the neighboring features, and the sum of the weight values. A positive Z-score indicates clustering, while a negative Z-score indicates dispersion (Winona State University, 2011).

\section{Results}

The results of the spatial autocorrelation analysis using ArcGIS are summarized in Table 2. The coefficients show the effect of a variable in a zone on the distribution pattern of the features in the surrounding zones. All the $Z$-scores are statistically significant with an alpha level of 0.01 percent. Given the Z-score values, there is a likelihood of less than $1 \%$ that these clustered patterns could be the result of the random chance. The larger the positive Z-score is, the more intense the clustering of the high values would be. Similarly, the smaller the negative $Z$-score is, the more intense the clustering of the low values would be.

\{Insert Table 2 here\}

According to the information presented in Figure 1, the areas that are most poorly served are census tracts with a low rate of access to the provision of the bus service (and the lower bus service frequency), and their neighbors also have low rates of access to the bus services. These are highly concentrated at the fringes of the metropolitan of Shiraz with the predominantly low-income communities. At the same time, the majority of the unemployed people, the immigrants, and the youths live in such areas. In contrast, the central West and the North-West of the city are occupied by those with better social demography features such as employment and education, and with greater access to the bus services (and the greater bus service frequency).

\section{Discussion}

Through linking the accessibility of the bus services to the vulnerable and disadvantaged populations (those who live at the urban fringe) directly, our examination of the spatial distribution of the providers of the bus service offers an exploration of the differential access to the bus services. In fact, all these maps and figures together can be used to explore the issue of inequity in the distribution of the bus services dealing with the geographical distribution of Shiraz economy, education, and employment groups.

The planning practice is now started to offer the potential opportunities for coping with the challenge of the social sustainability. The advocates of the sustainable development are drawing some connections between the continued suburbanization of jobs and housing (Deakin, 2007). In this regard, the advocates of the bus passengers - largely minorities - may challenge the decisions of the transit authority to spend a massive amount of budget on some center-oriented civil projects, while cutting the bus services in peripheral areas. Furthermore, through considering other factors restricting the travel for the disadvantaged groups, the spatial equity of the bus services can be better recognized. In fact, the social inequity is not only due to the accessibility feature, but also the economical, physiological, multi-dimensional and a mix of financial constraints, physical barriers, time budgets, access difficulties, and psychological components, such as fear, all come together in several ways to limit the use of the transportation services.

\section{Conclusion}

The research provided some statistically significant evidence revealing that the poor accessibility is associated with both the low-income neighborhoods and the neighborhoods with the disproportionately high populations of the migrated, less-educated, unemployed, and low-income groups. The policy implication is that some modifications need to be made in the transportation planning and policy so as to achieve a better distribution of the public transportation services in the hope of increasing the level of the service for the minority groups and the economically disadvantaged communities.

Although the correlation between the transportation and the social deprivation has been broadly studied, more direct investigation into the transportation part of the social exclusion is needed. Social disadvantage may happen because of the inability of the people to the physically accessible opportunities. However, coping with such concerns needs not only some modifications to the transportation system, but also some policies to tackle 
those reasons that limit an individual's movement such as cost and time (Church et al., 2000). Through considering these issues, the spatial equity of the bus services for the different social groups can be better recognized. Other aspects of the public bus equity such as the allocation of funding among the agencies, and the distribution of the subsidies among the individual users or classes of the transit users would significantly alter the debates over the transit equity.

\section{Acknowledgments}

This paper has arisen from the research project entitled: "evaluating the privatization process of Shiraz public bus system" conducted by the authors at Shiraz University in 2010. The authors would like to appreciate the help of Shiraz Organization of Public Bus for providing financial support and giving access to the information used here.

\section{Author Disclosure Statement}

The authors have no conflicts of interest or financial ties to disclose.

\section{References}

Anselin, L., \& Bera, A. (1998). Spatial Dependence in Linear Models with an Introduction to Spatial Econometrics. In H. U. Giles, Handbook of Applied Econometrics Statistics. New York: Marcel Dekker.

Church, A., Frost, M., \& Sullivan, K. (2000). Transport and social exclusion in London. Transport Policy (7), 195-205. doi:10.1016/S0967-070X(00)00024-X, http://dx.doi.org/10.1016/S0967-070X(00)00024-X

Currie, G., Richardson, T., Smyth, P., Vella-Brodrick, D., Hine, J., Lucas, K., et al. (2010). Investigating links between transport disadvantage, social exclusion and well-being in Melbourn. Research in Transportation Economics Journal , 29 (1), 287-295. doi:10.1016/j.retrec.2010.07.036, http://dx.doi.org/10.1016/j.retrec.2010.07.036

Deakin, E. (2007). Equity and environmental justice in sustainable transportation: Toward a research agenda. In Institutions and sustainable transport: Regulatory reform in advanced economies, Rietveld, P. \& Stough, R.R. (eds.). Cheltenham, UK: Edward Elgar, 51-69.

Delbosc, A., \& Currie, G. (2011). Exploring the relative influences of transport disadvantage and social exclusion on well-being. Transport Policy , 10-16. doi:10.1016/j.tranpol.2011.01.011, http://dx.doi.org/10.1016/j.tranpol.2011.01.011

Dodson, J., Gleeson, B., \& Sipe, N. (2004). Transport disadvantage and social status: overview of literature and methods. Brisbane: Urban Policy Program, Griffith University.

Garrett, M., \& Taylor, B. (1999). Reconsidering social equity in public transit. Berkeley Planning Journal , 13, 6-27. doi:10.1080/01441640902811304, http://dx.doi.org/10.1080/01441640902811304

Grengs, J. (2001). Does Public Transit Counteract the Segregation of Carless Households? Measuring Spatial Patterns of Accessibility with GIS. Transportation Research Record: Journal of the Transportation Research Board , 1753, 3-10. doi:10.3141/1753-01, http://dx.doi.org/10.3141/1753-01

Heiser, B. (1995). The Nature and Causes of Transport Disability in Britain and How to Overcome It. In G. Zarb, Removing Disabling Barriers. London: Policy Studies Institute.

Hurrni, A. (2006). Transport and social disadvantage in Western Sydney. Western Sydney Community Forum, Sydney.

Johnson, L. (2005). Big Roads, No Transport-Community Mapping for Transport Improvements. Brisbane: Urban Research Program, Griffith University, Queensland.

Litman, T. (2011). Evaluating Transportation Equity Guidance For Incorporating Distributional Impacts in Transportation Planning. Victoria Institute of Transport Planning, Victoria.

Messner, S., Anselin, L., Baller, R., Hawkins, D., Deane, G., \& Tolnay, S. (1999). The Spatial Patterning of County Homicide Rates: An Application of Exploratory Spatial Data Analysis. Journal of Quantitative Criminology , 15 (4), 423-450. doi:10.1234/12345678, http://dx.doi.org/10.1234/12345678

Oxford Dic. website, 2. (2011). Retrieved 4 11, 2011, from oxford-dictionaries: http://oxforddictionaries.com/definition/equity?view=uk.

Smoyer-Tomic, K. E., Hewko, J. N., \& Hodgson, J. (2004). Spatial Accessibility and Equity of Playgrounds in Edmonton. The Canadian Geographer (48), 41-50. doi:10.1111/j.0008-3658.2004.00061.x, http://dx.doi.org/10.1111/j.0008-3658.2004.00061.x 
Talen, E., \& Anselin, L. (1998). Assessing spatial equity: an evaluation of measures of accessibility to public playgrounds. Environment and Planning A , 30, 595-613. doi:10.1068/a300595, http://dx.doi.org/10.1068/a300595

TEAM, U. M. (2008). Overview of Public Transportation in Middle-East and North Africa. UITP (The International Association of Public Transport).

Tsou, K.-W., Hung, Y.-T., \& Chang, Y.-L. (2005). An accessibility-based integrated measure of relative spatial equity in urban public facilities. Cities, 22 (6), 424-435. doi:10.1234/12345678, http://dx.doi.org/10.1234/12345678

Wang, F. (2003). Job Proximity and Accessibility for Workers of Various Wage Groups. Urban Geography, 24 (3), 253-271. doi:10.1186/1476-072X-10-11, http://dx.doi.org/10.1186/1476-072X-10-11

Wikipedia (2011). Retrieved 4 11, 2011, from wikipedia: http://en.wikipedia.org/wiki/Social_equality.

Wilson, L.-M. (2003). An Overview of the Literature on Disability and Transport Disability Rights Commission. London.

Winona State University (2011). Retrieved 5 11, 2011, from Winona State University: http://course1.winona.edu/thooks/documents/GeostatisticsHandout16.docx.

Table 1. Statistical description of the variables

\begin{tabular}{|c|c|c|c|c|c|c|}
\hline & Definition & Min. & Max. & Avg. & Std. Dev. & No. of Cases \\
\hline $\begin{array}{l}\text { Bus } \\
\text { accessibility }\end{array}$ & $\begin{array}{l}\text { Network distance based } \\
\text { on Manhattan Distance } \\
\text { method }(\mathrm{m})\end{array}$ & 1 & 1921.483 & 274.617 & 239.182 & 10471 \\
\hline $\begin{array}{l}\text { Bus frequency } \\
\text { density }\end{array}$ & $\begin{array}{l}\text { Bus service frequency } \\
\text { per area (ha) }\end{array}$ & 0 & 0.267 & 0.029 & 0.034 & 10453 \\
\hline Unemployment & $\begin{array}{llr}\text { Share } & \text { of } & \text { total } \\
\text { workforce } & \text { who } & \text { are } \\
\text { unemployed } & & \end{array}$ & 0 & 0.571 & 0.044 & 0.060 & 10471 \\
\hline Immigrants & $\begin{array}{l}\text { Share of those reported } \\
\text { as immigrated }\end{array}$ & 0 & 1 & 0.118 & 0.128 & 10471 \\
\hline Illiteracy & $\begin{array}{l}\text { Share of aged } 6 \text { years } \\
\text { and above who are not } \\
\text { educated }\end{array}$ & 0 & 1 & 0.059 & 0.074 & 10471 \\
\hline Young & $\begin{array}{l}\text { Share of those aged } \\
\text { between } 6 \text { and } 25 \text { years }\end{array}$ & 0 & 1 & 0.295 & 0.183 & 10471 \\
\hline Aged over 65 & $\begin{array}{l}\text { Share of aged } 6 \text { years } \\
\text { and above who are not } \\
\text { educated }\end{array}$ & 0 & 0.441 & 0.035 & 0.041 & 10471 \\
\hline Disabled & $\begin{array}{l}\text { Share of those reported } \\
\text { as disabled }\end{array}$ & 0 & 0.588 & 0.011 & 0.019 & 10471 \\
\hline
\end{tabular}

(Source: IBS, 2006)

Table 2. Summary of spatial autocorrelation report

\begin{tabular}{|c|c|c|}
\hline Variable & Moran's Index & z-score \\
\hline Bus service frequency & 0.799 & 323.299 \\
\hline Unemployment & 0.158 & 48.666 \\
\hline Immigration & 0.012 & 6.524 \\
\hline Illiteracy & 0.467 & 144.283 \\
\hline Young & 0.398 & 122.829 \\
\hline Elderly & 0.259 & 104.704 \\
\hline Disability & 0.086 & 35.256 \\
\hline
\end{tabular}

Note. $\mathrm{p}<0.01$. 


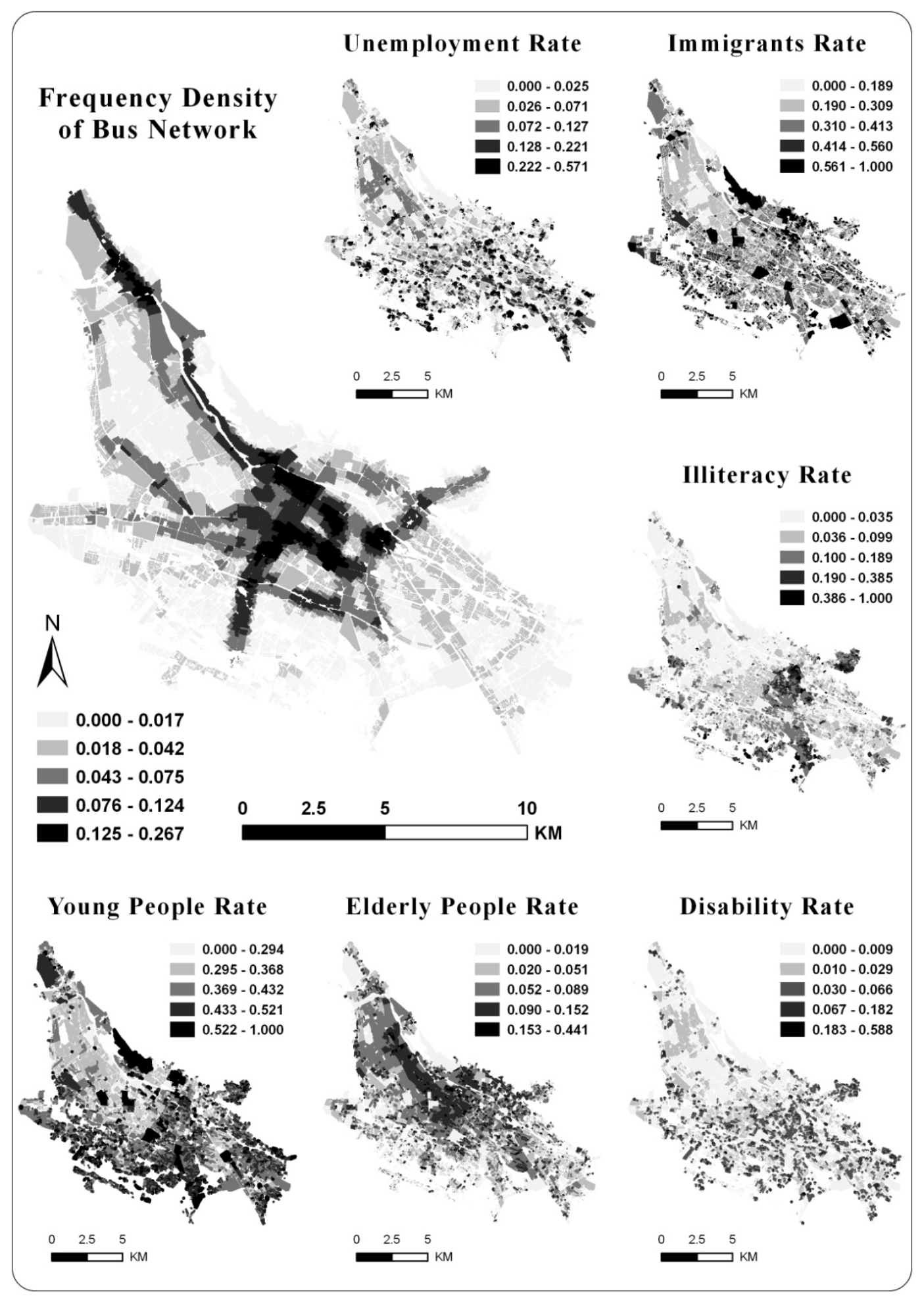

Figure 1. Spatial distribution of public bus services and socially-disadvantaged groups throughout Metropolitan Shiraz 